Review began 01/10/2022 Review ended 01/27/2022 Published 01/28/2022

๑) Copyright 2022

Lehrer et al. This is an open access article distributed under the terms of the Creative Commons Attribution License CC-BY 4.0. which permits unrestricted use, distribution, and reproduction in any medium, provided the original author and source are credited.

\section{Constipation and Cigarette Smoking Are Independent Influences for Parkinson's Disease}

\author{
Steven Lehrer ${ }^{1}$, Peter H. Rheinstein ${ }^{2}$ \\ 1. Radiation Oncology, Icahn School of Medicine at Mount Sinai, New York, USA 2. Family Medicine, Severn Health \\ Solutions, Severna Park, USA
}

Corresponding author: Steven Lehrer, stevenlehrer@hotmail.com

\section{Abstract \\ Background}

Tobacco smokers have reduced Parkinson's disease (PD) risk. Some patients with PD experience constipation long before they develop mobility problems, and constipation is a frequent complaint of people who try to stop smoking. Recently, the gut microbiome has been implicated in PD.

\section{Methods}

In the present study, we analyzed the relationship between smoking and constipation in subjects with PD and controls. We wished to determine whether the effects of smoking and constipation were independent or whether they might be interrelated. To evaluate the relationship, we used a cohort of subjects from the UK Biobank (UKB).

\section{Results}

In 501,174 subjects, the decreased risk of Parkinson's disease with increased smoking was significant ( $\mathrm{p}<$ 0.001, two-tailed Fisher's exact test). The increased risk of constipation in subjects with PD was significant ( $p=0.001$, two-tailed Fisher's exact test). Logistic regression was performed; sex, age, constipation, and smoking were the independent variables, and PD present or absent was the dependent variable. The PD odds ratio (OR) for males was 1.790 (95\% confidence interval (CI): 1.629-1.966) times that for females, indicating that PD is more common in men. The risk of PD increased by 1.140 (95\% CI: 1.131-1.149) with every year of age. Constipation increased the risk of PD by 4.043 (95\% CI: 1.901-8.599). Smoking diminished PD risk by 0.772 (95\% CI: 0.690-0.863). Drinking coffee was associated with a reduced risk of PD (OR: 0.815 (95\% CI: 0.730-0.909). Drinking tea reduced PD risk by 0.979 (95\% CI: 0.962-0.997) for each cup per day. The effects of sex, age, constipation, smoking, drinking coffee, and drinking tea were independent and significant.

\section{Conclusion}

Our analysis suggests that the favorable effect of smoking on PD is independent of the detrimental effect of constipation. Smoking reduces PD risk because it not only stimulates the bowel to empty and prevents constipation but also alters the gut microbiome. Another factor, perhaps the tobacco component diterpenoids, may be responsible for the PD risk-reducing effect.

Categories: Neurology

Keywords: parkinson's disease, diterpenes, risk factors, smoking, constipation

\section{Introduction}

Parkinson's disease (PD) is a long-term degenerative disorder of the central nervous system that mainly affects the motor system. The cause of PD is unknown, with both inherited and environmental factors involved. Recently, the gut microbiome has been implicated $[1,2]$.

Tobacco smokers have reduced PD risk. The inverse relationship between smoking and PD is dosedependent: the more a person smokes, the less chance that he or she will develop PD [3].

Some patients with PD experience constipation long before they develop mobility problems, and constipation is a frequent complaint of people who try to stop smoking. One in six smokers attempting to quit will become constipated; for one in 11 , the problem is severe. Constipation is reduced but still reported if nicotine replacement therapy is used [4].

Coffee and tea consumption are associated with reduced PD risk, as well as reduced risk of Alzheimer's disease $(\mathrm{AD})[5,6]$.

In the present study, we analyzed the relationship between smoking and constipation in subjects with PD 
and controls. Our aim was to determine whether the effects of smoking and constipation were independent or whether they might be interrelated. To evaluate the relationship, we used a cohort of subjects from the UK Biobank (UKB).

\section{Materials And Methods}

\section{Methods}

The UK Biobank is a large prospective observational study of men and women. Participants were recruited from across 22 centers located throughout England, Wales, and Scotland between 2006 and 2010 and continue to be longitudinally followed for the capture of subsequent health events [7]. Follow-up health information is provided by linkage to primary care electronic health records, death and cancer registries, and hospital admission records [8]. Some participants had PD at the beginning of the study. Our UK Biobank application was approved as UKB project 57245 (SL and PHR).

\section{Study design and inclusion criteria}

Our analysis included all subjects with PD. The diagnosis was ascertained using the 10th revision of the International Classification of Diseases (ICD10 G20). Constipation was recorded in UKB category 100074, medical conditions, data field 20002, non-cancer illness, and self-report code 1599 constipation. Smoking information was from UKB category 100058, data field 1239, and current tobacco smoking. The three valid responses were as follows: 0 - no, 1 - only occasionally, and 2 - yes on most or all days.

\section{Exclusion criteria}

We did not include subjects missing any of the inclusion criteria or make corrections for missing data.

\section{Ethics approval}

UK Biobank has approval from the Northwest Multi-center Research Ethics Committee (MREC), which covers the UK. It also sought approval in England and Wales from the Patient Information Advisory Group (PIAG) for gaining access to information that would allow it to invite people to participate. PIAG has since been replaced by the National Information Governance Board for Health \& Social Care (NIGB). In Scotland, UK Biobank has approval from the Community Health Index Advisory Group (CHIAG).

Data processing was performed using Minerva, a Linux mainframe with Centos 7.6, at the Icahn School of Medicine at Mount Sinai. We used the UK Biobank Data Parser (ukbb parser), a python-based package that allows easy interfacing with the large UK Biobank dataset [9]. SPSS version 25.0 (IBM Corp., Armonk, NY, USA) was used for data analysis (chi-square test, Fisher's exact test, and logistic regression).

\section{Results}

We analyzed data from 501,174 subjects. The age at enrollment was $56 \pm 8$ years (mean \pm SD). Of the subjects, $56 \%$ were women and $44 \%$ were men, and $98 \%$ were White and British. The subjects were followed for $13.7 \pm$ 2.7 months.

Table 1 shows the smoking history of the 501,174 subjects versus Parkinson's disease. The decrease in Parkinson's disease with increased smoking was significant ( $p<0.001$, two-tailed Fisher's exact test). 


\section{Cureus}

\begin{tabular}{|c|c|c|c|}
\hline & & Parkinson's disease & \\
\hline Smoking & & No & Yes \\
\hline \multirow[t]{2}{*}{ No } & Count & 446,389 & 1,808 \\
\hline & $\%$ within smoking & $99.60 \%$ & $0.40 \%$ \\
\hline \multirow[t]{2}{*}{ Occasionally } & Count & 13,697 & 37 \\
\hline & $\%$ within smoking & $99.70 \%$ & $0.30 \%$ \\
\hline \multirow[t]{2}{*}{ Yes } & Count & 39,160 & 83 \\
\hline & $\%$ within smoking & $99.80 \%$ & $0.20 \%$ \\
\hline \multirow[t]{2}{*}{ Total } & Count & 499,246 & 1,928 \\
\hline & \% within smoking & $99.60 \%$ & $0.40 \%$ \\
\hline
\end{tabular}

TABLE 1: Smoking history of the 501,174 subjects versus Parkinson's disease.

The three valid responses were no, only occasionally, and yes on most or all days. The decrease in Parkinson's disease with increased smoking was significant $(p<0.001$, two-tailed Fisher's exact test).

Table 2 shows constipation in 501,174 subjects, PD and controls. The increase in constipation in subjects with PD is significant ( $\mathrm{p}=0.001$, two-tailed Fisher's exact test).

\begin{tabular}{|c|c|c|c|c|}
\hline & & Parkinson's & & Total \\
\hline Constipation & & No & Yes & \\
\hline \multirow[t]{2}{*}{ No } & Count & 498,850 & 1,931 & 500,781 \\
\hline & \% within constipation & $99.60 \%$ & $0.40 \%$ & $100 \%$ \\
\hline \multirow[t]{2}{*}{ Yes } & Count & 396 & 7 & 403 \\
\hline & \% within constipation & $98.30 \%$ & $1.70 \%$ & $100 \%$ \\
\hline \multirow[t]{2}{*}{ Total } & Count & 499,246 & 1,938 & 501,184 \\
\hline & \% within constipation & $99.60 \%$ & $0.40 \%$ & $100 \%$ \\
\hline
\end{tabular}

TABLE 2: Constipation in 501,174 subjects, PD and controls.

The increase in constipation in subjects with PD is significant ( $p=0.001$, two-tailed Fisher's exact test).

Coffee drinking in 501,184 subjects is tabulated in Table 3. PD incidence was lower in subjects who drank caffeinated coffee, but not in subjects who drank decaffeinated coffee or did not drink coffee. 


\section{Cureus}

\begin{tabular}{|c|c|c|c|c|}
\hline Coffee & & Control & Parkinson's & Total \\
\hline \multirow[t]{2}{*}{ None } & Count & 116,544 & 467 & 117,011 \\
\hline & $\%$ within column & $23.30 \%$ & $24.10 \%$ & $23.30 \%$ \\
\hline \multirow[t]{2}{*}{ Decaf } & Count & 73,965 & 373 & 74,338 \\
\hline & $\%$ within column & $14.80 \%$ & $19.20 \%$ & $14.80 \%$ \\
\hline \multirow[t]{2}{*}{ Instant } & Count & 214,011 & 792 & 214,803 \\
\hline & $\%$ within column & $42.90 \%$ & $40.90 \%$ & $42.90 \%$ \\
\hline \multirow[t]{2}{*}{ Ground } & Count & 87,611 & 287 & 87,898 \\
\hline & $\%$ within column & $17.50 \%$ & $14.80 \%$ & $17.50 \%$ \\
\hline \multirow[t]{2}{*}{ Other } & Count & 7,115 & 19 & 7,134 \\
\hline & $\%$ within column & $1.40 \%$ & $1 \%$ & $1.40 \%$ \\
\hline \multirow[t]{2}{*}{ Total } & Count & 499,246 & 1,938 & 501,184 \\
\hline & \% within column & $100 \%$ & $100 \%$ & $100 \%$ \\
\hline
\end{tabular}

\section{TABLE 3: Coffee drinking in 501,184 subjects.}

Coffee: none, decaffeinated coffee (any type), instant coffee, ground coffee (includes espresso and filter), and other types of coffee

The variability was significant $(p<0.001$, two-tailed chi-square)

Table 4 displays logistic regression with 95\% confidence intervals (CIs). Sex, age, constipation, smoking, drinking coffee, and drinking tea were the independent variables, and PD present or absent was the dependent variable. The PD odds ratio (OR) for males was 1.790 times that for females, indicating that PD is more common in men. The risk of PD increased by 1.140 with every year of age. Constipation increased the risk of PD by 4.043. Smoking (yes or no) diminished PD risk by 0.772 . Drinking coffee was associated with a reduced risk of PD (OR: 0.815). Drinking tea reduced PD risk by 0.979 for each cup per day. The effects of sex, age, constipation, smoking, drinking coffee, and drinking tea were independent and significant.

\begin{tabular}{|c|c|c|c|c|}
\hline & $95 \%$ LB & OR & $95 \%$ UB & p value \\
\hline Sex & 1.629 & 1.790 & 1.966 & $<0.001$ \\
\hline Age & 1.131 & 1.140 & 1.149 & $<0.001$ \\
\hline Constipation & 1.901 & 4.043 & 8.599 & $<0.001$ \\
\hline Smoking & 0.690 & 0.772 & 0.863 & $<0.001$ \\
\hline Drinking coffee & 0.730 & 0.815 & 0.909 & $<0.001$ \\
\hline Drinking tea & 0.962 & 0.979 & 0.997 & 0.017 \\
\hline
\end{tabular}

TABLE 4: Logistic regression with 95\% confidence intervals (lower bound (LB) and upper bound (UB)).

\section{Discussion}

The gut microbiome's influence on the brain is being actively studied. In one report, mice without gut bacteria were less anxious than their healthy equivalents. In 2017, a systematic review and meta-analysis demonstrated that people with constipation are at higher risk of developing PD compared with those without and that constipation can predate PD diagnosis by over a decade [10]. The relatively low incidence of constipation we found in UKB patients with PD (1.7\%) could be attributed to the healthy lifestyle of the UKB 
subjects compared with the general British population [11]. The present study did not investigate the influence of the gut microbiome on PD and smoking.

In $\mathrm{PD}$, the protein $\alpha$-synuclein misfolds. The misfolded protein causes more misfolds until harmful clumps of Lewy bodies form in the brain. Gut bacteria can produce proteins that have a similar structure to $\alpha$ synuclein, so bacterial proteins might be providing a template for misfolding [12]. A strain of Escherichia coli in the gut makes a protein, curli, which can stimulate other proteins, including $\alpha$-synuclein, to misfold. The misfolded proteins might transmit the aberration up the vagus nerve to the brain, where misfolded $\alpha$ synuclein is linked to PD symptoms [13].

Stomach ulcers were once treated by removing all or part of the vagus nerve to reduce acid production in the stomach. Interestingly, people who had undergone this procedure had less risk of Parkinson's disease [14].

The reasons for the inverse association between tobacco smoking and PD are not fully understood. Some studies have suggested that nicotine, such as caffeine, may have neuroprotective properties and stimulate the release of dopamine. However, high-dose transdermal nicotine in patients with PD was not beneficial [15]. Therefore, other components of tobacco may be responsible for the neuroprotective effect. Although smoking may reduce the risks of PD, the reduction in risk is small, and most likely, the harmful effects of tobacco outweigh the protective effects.

Tobacco has a long history of medicinal applications [16]. The leaves and juice were much used for skin disorders, possibly including basal cell cancer. Of most interest in Parkinson's disease are the diterpenes in tobacco.

Diterpenes are a class of chemical compounds composed of four isoprene units. They are biosynthesized by plants, animals, and fungi via the 3-hydroxy-3-methylglutaryl coenzyme A (HMG-CoA) reductase pathway, with geranylgeranyl pyrophosphate being a primary intermediate. Diterpenes form the basis for biologically important compounds such as retinol, retinal, and phytol. They are antimicrobial, neuroprotective, and antiinflammatory [17,18]. Diterpenes are present in coffee and tea, as well as in tobacco leaves, and coffee and tea drinkers have reduced PD risk, as well as AD risk $[6,19]$.

Tobacco plants use nicotine and diterpenoids to protect themselves from pests such as tobacco hornworms. Diterpenoids are extremely poisonous. Tobacco plants have evolved a complex process to maintain a balance between self-defense and self-poisoning. Two cytochrome P450 enzymes act in the biosynthesis pathway of 17-hydroxygeranyllinalool diterpene glycosides in wild tobacco (Nicotiana attenuata) to prevent the accumulation of hazardous diterpene derivatives. After ingestion, the same diterpene derivatives develop in an insect herbivore, causing toxicity by blocking sphingolipid production in both the plant and the insect [20]. Diterpenes are active against Parkinson's disease and other forms of neurodegeneration and have been suggested as therapeutic agents [21].

Our results agree with previous studies that drinking coffee, but not decaffeinated coffee, and tea protect against PD [22]. The protection may be partly due to caffeine, which is both a central nervous system stimulant and neuroprotectant [5,23-25]. However, the diterpene content of coffee and tea may contribute to the $\mathrm{PD}$ protective effect, as well as a protective effect against $\mathrm{AD}$ [26], since decaffeinated coffee has markedly reduced levels of diterpene esters [27].

\section{Limitations}

Our study is limited due to the fact that it is retrospective and we were unable to assess the severity or duration of PD relative to constipation and cigarette smoking. We had only ICD10 G20 and no other details of the PD.

\section{Conclusions}

Our analysis suggests that the favorable effect of smoking on PD is independent of the detrimental effect of constipation. Smoking reduces PD risk because it not only stimulates the bowel to empty and prevents constipation but also alters the gut microbiome. Another factor, perhaps the tobacco component diterpenoids, may be responsible for the PD risk-reducing effect.

The search for PD therapy in tobacco should not begin and end with nicotine patches. Further studies are certainly warranted.

\section{Additional Information}

\section{Disclosures}

Human subjects: Consent was obtained or waived by all participants in this study. UK Biobank issued approval n/a. UK Biobank has approval from the Northwest Multi-center Research Ethics Committee (MREC), which covers the UK. It also sought approval in England and Wales from the Patient Information Advisory 
Group (PIAG) for gaining access to information that would allow it to invite people to participate. PIAG has since been replaced by the National Information Governance Board for Health \& Social Care (NIGB). In Scotland, UK Biobank has approval from the Community Health Index Advisory Group (CHIAG). Animal subjects: All authors have confirmed that this study did not involve animal subjects or tissue. Conflicts of interest: In compliance with the ICMJE uniform disclosure form, all authors declare the following: Payment/services info: All authors have declared that no financial support was received from any organization for the submitted work. Financial relationships: All authors have declared that they have no financial relationships at present or within the previous three years with any organizations that might have an interest in the submitted work. Other relationships: All authors have declared that there are no other relationships or activities that could appear to have influenced the submitted work.

\section{Acknowledgements}

This work was supported in part through the computational resources and staff expertise provided by Scientific Computing at the Icahn School of Medicine at Mount Sinai. The research reported in this paper was supported by the Office of Research Infrastructure of the National Institutes of Health under award numbers S10OD018522 and S10OD026880. The content is solely the responsibility of the authors and does not necessarily represent the official views of the National Institutes of Health.

\section{References}

1. Willyard C: How gut microbes could drive brain disorders . Nature. 2021, 590:22-5. 10.1038/d41586-02100260-3

2. Fitzgerald E, Murphy S, Martinson HA: Alpha-synuclein pathology and the role of the microbiota in Parkinson's disease. Front Neurosci. 2019, 13:369. 10.3389/fnins.2019.00369

3. Mappin-Kasirer B, Pan H, Lewington S, Kizza J, Gray R, Clarke R, Peto R: Tobacco smoking and the risk of Parkinson disease: a 65-year follow-up of 30,000 male British doctors. Neurology. 2020, 94:e2132-8. 10.1212/WNL.0000000000009437

4. Hajek P, Gillison F, McRobbie H: Stopping smoking can cause constipation. Addiction. 2003, 98:1563-7. 10.1046/i.1360-0443.2003.00497.x

5. Hu G, Bidel S, Jousilahti P, Antikainen R, Tuomilehto J: Coffee and tea consumption and the risk of Parkinson's disease. Mov Disord. 2007, 22:2242-8. 10.1002/mds.21706

6. Eskelinen MH, Kivipelto M: Caffeine as a protective factor in dementia and Alzheimer's disease . I Alzheimers Dis. 2010, 20 Suppl 1:S167-74. 10.3233/JAD-2010-1404

7. Arthur RS, Wang T, Xue X, Kamensky V, Rohan TE: Genetic factors, adherence to healthy lifestyle behavior, and risk of invasive breast cancer among women in the UK Biobank. J Natl Cancer Inst. 2020, 112:893-901. 10.1093/inci/djz241

8. Khanji MY, Aung N, Chahal CA, Petersen SE: COVID-19 and the UK Biobank-opportunities and challenges for research and collaboration with other large population studies. Front Cardiovasc Med. 2020, 7:156. $10.3389 / \mathrm{fcrm} .2020 .00156$

9. Zhu A, Salminen LE, Thompson PM, Jahanshad N: The UK Biobank Data Parser: a tool with built in and customizable filters for brain studies. Organization for Human Brain Mapping Rome, Italy. 2019,

10. Adams-Carr KL, Bestwick JP, Shribman S, Lees A, Schrag A, Noyce AJ: Constipation preceding Parkinson's disease: a systematic review and meta-analysis. J Neurol Neurosurg Psychiatry. 2016, 87:710-6. 10.1136/jnnp-2015-311680

11. Fry A, Littlejohns TJ, Sudlow C, et al.: Comparison of sociodemographic and health-related characteristics of UK Biobank participants with those of the general population. Am J Epidemiol. 2017, 186:1026-34. 10.1093/aje/kwx246

12. Friedland RP: Mechanisms of molecular mimicry involving the microbiota in neurodegeneration. I Alzheimers Dis. 2015, 45:349-62. 10.3233/JAD-142841

13. Sampson TR, Challis C, Jain N, et al.: A gut bacterial amyloid promotes $\alpha$-synuclein aggregation and motor impairment in mice. Elife. 2020, 9:10.7554/eLife.53111

14. Svensson E, Horváth-Puhó E, Thomsen RW, Djurhuus JC, Pedersen L, Borghammer P, Sørensen HT: Vagotomy and subsequent risk of Parkinson's disease . Ann Neurol. 2015, 78:522-9. 10.1002/ana.24448

15. Villafane G, Thiriez C, Audureau E, et al.: High-dose transdermal nicotine in Parkinson's disease patients: a randomized, open-label, blinded-endpoint evaluation phase 2 study. Eur J Neurol. 2018, 25:120-7. 10.1111/ene.13474

16. Charlton A: Medicinal uses of tobacco in history. J R Soc Med. 2004, 97:292-6. 10.1258/jrsm.97.6.292

17. Kim CS, Subedi L, Kim SY, Choi SU, Kim KH, Lee KR: Diterpenes from the trunk of Abies holophylla and their potential neuroprotective and anti-inflammatory activities. J Nat Prod. 2016, 79:387-94. 10.1021/acs.jnatprod.5b01053

18. Yan N, Du Y, Liu X, Zhang H, Liu Y, Zhang Z: A review on bioactivities of tobacco cembranoid diterpenes . Biomolecules. 2019, 9:10.3390/biom9010030

19. Gross G, Jaccaud E, Huggett AC: Analysis of the content of the diterpenes cafestol and kahweol in coffee brews. Food Chem Toxicol. 1997, 35:547-54. 10.1016/s0278-6915(96)00123-8

20. Li J, Halitschke R, Li D, et al.: Controlled hydroxylations of diterpenoids allow for plant chemical defense without autotoxicity. Science. 2021, 371:255-60. 10.1126/science.abe4713

21. Islam MT, da Silva CB, de Alencar MV, Paz MF, Almeida FR, Melo-Cavalcante AA: Diterpenes: advances in neurobiological drug research. Phytother Res. 2016, 30:915-28. 10.1002/ptr.5609

22. Ascherio A, Zhang SM, Hernán MA, Kawachi I, Colditz GA, Speizer FE, Willett WC: Prospective study of caffeine consumption and risk of Parkinson's disease in men and women. Ann Neurol. 2001, 50:56-63. 10.1002/ana.1052

23. Tan EK, Tan C, Fook-Chong SM, et al.: Dose-dependent protective effect of coffee, tea, and smoking in 


\section{Cureus}

Parkinson's disease: a study in ethnic Chinese. J Neurol Sci. 2003, 216:163-7. 10.1016/j.jns.2003.07.006

24. Kandinov B, Giladi N, Korczyn AD: The effect of cigarette smoking, tea, and coffee consumption on the progression of Parkinson's disease. Parkinsonism Relat Disord. 2007, 13:243-5.

10.1016/j.parkreldis.2006.11.004

25. Popat RA, Van Den Eeden SK, Tanner CM, et al.: Coffee, ADORA2A, and CYP1A2: the caffeine connection in Parkinson's disease. Eur J Neurol. 2011, 18:756-65. 10.1111/j.1468-1331.2011.03353.x

26. Habtemariam S: The therapeutic potential of rosemary (Rosmarinus officinalis) diterpenes for Alzheimer's disease. Evid Based Complement Alternat Med. 2016, 2016:2680409. 10.1155/2016/2680409

27. Moeenfard M, Erny GL, Alves A: Variability of some diterpene esters in coffee beverages as influenced by brewing procedures. J Food Sci Technol. 2016, 53:3916-27. 10.1007/s13197-016-2378-6 